\title{
You're Hired! Changing Students' Attitudes Towards Engineering
}

\begin{abstract}
With the growing need for qualified employees in STEM-based careers, it is critical to develop activities for middle and high school students to increase their awareness of opportunities in these areas. With proper design, increasing awareness of STEM-based careers in conjunction with overcoming current stereotypes can lead to a change in attitudes towards these various careers. Researchers at North Dakota State College of Science, along with the University of North Dakota and North Dakota State University, have developed 'You're Hired!', a project providing middle and high school students a hands-on, authentic experience in various engineering roles while assessing the change in a student's attitude towards the engineering profession. Project design also incorporates within this engaging STEM experience an opportunity in which students can hone their $21^{\text {st }}$ Century Skills such as collaboration, critical thinking and time management. As students conduct peer and self-assessments of their $21^{\text {st }}$ Century Skills throughout this project, school administrators are quick to recognize the benefit of implementing a single project that brings both STEM and $21^{\text {st }}$ Century Skills into their districts. Evaluation of the project's success includes a pre-survey and post-survey to determine the impact of the comprehensive project on student's attitudes towards engineering and engineeringrelated careers.

'You're Hired!' is a series of three STEM-based activities, given over the course of a school year, that requires students to work as a 'company' for an entire school day to find a solution to a relevant, present-day problem. At the end of each activity, the students communicate their solution to a community-led boardroom, comprised of school board members, community stakeholders and local industry representatives. The 'You're Hired!' project is designed to immerse students in an authentic real-world experience by incorporating the engineering design process and 21st Century Skills, and to track their progress in these areas throughout the year using peer- and self-assessments.

This research project uses both quantitative and qualitative analysis to analyze the data gathered during the project. The initial findings demonstrate that the 'You're Hired!' project appears to be effective in increasing the awareness and attitudes of students towards the field of engineering and engineering-related careers. This paper will present the details of the project, the methodology for data collection and analysis, and a discussion of the findings.
\end{abstract}

\section{Introduction}

Engineering touches almost every piece of the world we live in, from an online video chat to an artificial heart valve. Engineering careers are in high-demand within a wide array of industries, yet the general public has a limited perspective of these careers. ${ }^{[1]}$ Research has linked K-12 students' limited knowledge and/or negative image of engineering careers to the shortage in the number of college graduates receiving degrees in engineering. ${ }^{[2,3]}$ Students' images of engineering, also referred to as stereotypes, frequently identify engineers as car mechanics, 
construction workers or train operators. ${ }^{[4,5]}$ Other stereotypes include: engineering is boring, engineers work alone or at a computer, and engineers help society. ${ }^{[4,5,6]}$

Students' images of engineering stem from a variety of different sources: knowing engineers in their community, career expositions, friends or family members, class trips, guest speakers or media. ${ }^{[5,7,8]}$ Unfortunately, current methods of educating K-12 students about engineering and engineering careers have shown little impact, with the percentage of U.S. bachelor's degrees awarded in engineering remaining constant around $4.5 \%$ over the past decade, down from an average of $7.1 \%$ during the 1980 's. ${ }^{\text {[9] }}$ While it may appear beneficial to bring an engineer into the classroom to spend time with the students and talk about their profession, many students are often left with only a slight understanding of the guest engineer's career and fail to see themselves in the same role as that engineer. ${ }^{[10]}$ More effective methods of generating student interest in and understanding of engineering are needed.

\section{Changing Attitudes with Authentic Experience}

To meet the national engineering demand with more students choosing the engineering profession, students must first have a positive image of engineers and the engineering profession. 'If you want to change how people behave, you first have to change how they think. '[11] Recognizing that the engineering profession has had the same image for numerous years, innovative approaches must be taken to change this persistent and resistant view by providing personal experiences. ${ }^{[12]}$ Having a guest speaker talk about his/her engineering profession can become a personal, vicarious experience if the speaker is such a good storyteller that students dive into what the speaker is saying and feel like they too could be engineers doing the same work. However, the availability of these dynamic guest speakers is limited and even a great speaker may only spark the interest of students that relate to the specific engineering area presented. Field trips also provide a vicarious experience, but suffer from the same limitation where only a few students may envision themselves as the engineers working in that specific environment.

More promising are approaches that move beyond a vicarious experience, instead directly involving students in a personal, authentic experience where they take the role of an engineer. Such an experience will change a student's attitude and behavior towards engineering if the student can answer 'yes' to two questions: 1) can I do it? and 2) what is in it for me? ${ }^{[11,12,13]}$

Effective pre-engineering activities, such as robotics club and engineering camp, include key attributes that have been shown to positively influence students to successfully pursue and complete an engineering degree: self-motivation, use of problem-solving strategies, use of computer applications, and immediate feedback on success of efforts. ${ }^{[13]}$ Other research has highlighted key design factors that offer engagement with engineering: the 'wow' factor, simple yet effective ideas, social responsibility, potential for world-wide impact, and personal relevance. ${ }^{[5]}$ When looking into programs that impact all students, not just a select group that joins a club or camp, common themes regarding engineering education arise including: active learning/inquiry-based learning through hands on activities, interdisciplinary approaches which add a technological component, teacher engagement, curriculum supplements that connect to standards, and creating mentorships and partnerships that make engineers "cool". ${ }^{[14,15]}$ 
Work done by one successful program, Engineering is Elementary, has led to a list of inclusive principles as a starting point for resource design. The Engineering is Elementary principles

include much of the attributes listed above for other programs. [3] ${ }^{[16]}$

Including these key attributes, factors, and principles should increase the likelihood of positively impacting a broad range of students, as different individual students will respond best to different program elements. Changing attitudes towards engineering on a large scale will require that multiple influence strategies and project attributes be incorporated.

This paper describes initial results from an exciting new project, 'You're Hired!', that was designed to include many of these key elements, with the goal of improving student attitudes towards engineering. A brief description of the project, how it is typically implemented in middle and high schools, and how the key elements are incorporated is provided first. The methodology of a research project to assess attitude changes for students participating in the 'You're Hired!' project is then described. This is followed by presentation and discussion of the research project results, including a comparison of results for male and female students. We conclude with a summary of key findings and plans for future research.

\section{Project Description/Design}

The 'You're Hired!' project is designed to engage students in an intense, coherent set of STEMfocused experiences, which requires the use of the engineering design process and infuses $21^{\text {st }}$ Century Skills to solve real-world problems. The age of students participating in 'You're Hired!' ranged from $7^{\text {th }}$ grade to $12^{\text {th }}$ grade. While engineering outreach programs are being implemented throughout the entire K-12 range nationwide, ${ }^{[14,16-21]}$ many programs focus on middle to high school students because this is the age when students begin thinking about and planning their own paths in education. Students can do this by choosing classes to take in high school and thinking about options to pursue math or science related fields in college. ${ }^{[14,19-21]}$ Fifteen schools across multiple states had readily signed up to participate in the pilot project because 'You're Hired!' is an innovative way to meet their needs of (1) implementing interdisciplinary STEM experiences for all their students and teachers without burdening existing resources and (2) providing a method to assess and hone all students' $21^{\text {st }}$ Century Skills. The project also addresses industry's need for more students to enter STEM-related careers by providing the students with a positive, authentic experience of engineering, evaluated by the change in attitude towards these STEM-related careers. Ultimately, 'You're Hired!' is intended to be a proven piloted project which can be replicated, adapted to other contexts, and nationally scaled.

The 'You're Hired!' project has small groups of students work together as a 'company' for an entire school day to find a solution to a relevant, real-world problem. This provides an experience that incorporates many of the key attributes for successful pre-engineering activities. Students must be self-motivated to complete their tasks in a timely manner. Students also have to problem-solve in an active learning environment to come up with a solution to the given problem. Students use computer applications to make graphs and presentations for communicating their discovery/solution to a community-led boardroom, comprised of school administrators, school board members and local industry representatives including professional 
engineers. The boardroom will give the students immediate feedback on their efforts after each activity.

The 'You're Hired!' project is not just a onetime event; it is a series of three day-long activities that occur over the course of a school year to provide multiple authentic experiences of possible engineering careers, while incorporating the key factors for engagement with engineering. Individual 'You're Hired!' activities set learning in a real-world context by posing different problems with world-wide impact that require the expertise of different engineering disciplines (e.g., chemical and environmental engineers help clean up an oil spill using a nano-based coating). Problems are developed that will be of personal relevance to students (e.g., determining the effect texting has on reaction times and relating the experimental results to the dangers of texting while driving) and that can be described with simple engineering ideas. Introducing various engineering careers within the construct of solving socially relevant problems helps convey the diversity within the engineering profession. The variety of problems is also intended to increase the likelihood of individual students experiencing the 'wow' factor at least once during the year.

\section{'You're Hired!' Over the Course of a School Year}

The 'You're Hired!' project begins at a participating school prior to the first day-long activity with teachers organizing companies consisting of 6-8 students. Depending on the size of the school, if multiple grades are participating teachers can choose to mix students from the various grades in a company. The 'You're Hired!' project team also works with school principals to coordinate scheduling days, students, teachers, boardroom participants and other necessary approvals well in advance to ensure smooth project execution. Because the students are released from their regular classes for the day, the classrooms and teachers within the school become available during the project. With this design, schools quickly realize that they have the resources to make 'You're Hired!' a reality at their school.

\section{Breakdown of a 'You're Hired!' Day}

The basic framework of a day's activity ensures that schools are able to easily conduct the activity with minimal resources required, a key aspect when designing for scalability. The following breakdown is offered as a template, with flexibility to modify as needed.

The day starts out with an introduction of the problem statement for the given activity. The problem statements are designed to be simple yet effective so that students can dive into a creative solution. The open ended designs of the challenges use both qualitative and quantitative strategies to develop a solution. For the pilot year the three problem statements used with the schools were: 1) using nano-technology coated sand to clean up an oil spill, 2) experimenting with reaction times and creating a prototype to end texting while driving, and 3) creating a school lunch menu that follows all new nutrition standards. During the introduction to the activity students are given a packet of paper information along with an experiment kit. For example, in the oil spill design challenge students are given the following introduction: 


An environmentalist group known as Greener Ways has decided
to undertake the large task of safely cleaning up oil spills. It's
estimated that millions of gallons of oil enter the oceans each year,
from ship motors, natural leaking, and oil spills. The oil waste then
reaches the coastal shoreline and contaminates beach vegetation,
wildlife, and swimming environments.
Greener Ways has developed a break-through product that is
predicted to clean oil spills easily and effectively. They have
developed a product known as Magic Sand that they would like to
use to clean up such incidences.
Your company is a state of the art company that is very good at
cutting edge technology. Your company has been chosen to be one
of the finalists in our search for a company that will be able to use
the Magic Sand to clean up an oil spill.
Your company's tasks will be to:
-
-
Expearch
Advertise
- Market the product
- Come up with a presentation to convince us to use your
company over other leading companies.

Once the introduction is completed and the students break into their pre-determined companies the students must define their company, including a name, mission statement, logo and organizational roles. A company profile sheet calls out specific roles, requiring the students to take on specific tasks during the day. Typical roles include manager, advertising specialist, engineer, and technician. Each separate 'You're Hired!' day tailors the engineering and technology-related titles to the specific careers that would actually be working on the problem. This level of explicit detail provides the practical application of role responsibility in a STEM career and draws a strong connection between their one-day experience and a possible future career.

After the company is defined, the students work on developing their solution in a problembased/active learning environment for a majority of the school day (4-5 hours). During this time students conduct hands-on experiments, are engaged in real-world research, and are exposed to an authentic work-like environment in which every student has a job and is a part of a company/team.

Teachers play a key role during the day by providing content knowledge on a 'just-in-time' basis through a system of question vouchers. For the day-long activity each student group is given three vouchers that can be used for 5-minute question sessions with a teacher. These question sessions provide direct teacher instruction on the specific topics of immediate interest to students. Because these mini-lessons are student-instigated at a time of need, rather than force- 
fed by teachers at the beginning of the day before their importance is clear, students are in a much better position to understand the necessity of the information provided and its relevance to their problem-solving and investigating practices. Additionally, 'such just-in-time instruction promotes knowledge construction in a way that makes knowledge more available for future use in relevant contexts.' ${ }^{[22,23]}$ The number of vouchers is limited to encourage students to problem solve and collaborate together instead of immediately looking to a teacher for the "correct" answer.

Because the 'You're Hired!' activities build on knowledge students already have, all students are able to participate and they can do so independently from teachers. For example, with the oil spill activity, students are told that millions of gallons of oil are introduced to the oceans each year. The students are told they need to be able to convey this information to the boardroom to make them care about the issue. To do that, students need to convert the huge unimaginable number of 'millions of gallons' to a more approachable value such as ' $x$ ' number of classrooms full of oil is spilt. Students determine for themselves what they would like to compare the volume of oil spilt to (classrooms, swimming pools, bathtubs, etc.), and then use their knowledge of volume calculations and unit conversions to solve. Students are first introduced to volume calculations and unit conversions in 5th grade. ${ }^{[24]}$ In this way they provide an open-ended challenge where students can see how all their different classes merge together in a real-world application.

At the end of each activity the companies present their solution to the challenge in front of a boardroom comprised of school board members, school administrators, and local industry representatives including local engineers. The boardroom members score the companies on different aspects of the presentation including the engineering design process, teamwork, and creativity of the solution. The boardroom not only provides immediate feedback, but also includes recommendations for improvements, both of which enhance overall student learning by affirming that students' contributions and ideas have value.

You're Hired! is designed to be a series of short term interventions that give students authentic experiences that can later be built on in the classroom. During the activity teachers are available for student support, but also have the opportunity to stand back and observe student learning. This allows teachers to see gaps within students' ability to utilize educational material and take notes. In the following days in the classroom, teachers now have a personal experience for students to reflect on while revisiting key material. For example, an English teacher at one school realized that while students had learned about citations, many of the presentations did not use them correctly. That teacher was then able to revisit the topic in the classroom, using the You're Hired! activity as an example. During the next activity, the students did much better at understanding the importance of citing the information they found. As we continue to develop the 'You're Hired!' project, the addition of professional development for teachers will be a key component, including training on how to take You're Hired! teacher observations to the next level and allowing teachers to be able to reflect with the students on their experiences in the regular classroom.

\section{Methodology}


To research the effectiveness of the "You're Hired!' project at promoting positive attitudes towards engineering, pre- and post-surveys were used for summative evaluation of students' awareness and perceptions towards different aspects of engineering. Data from these surveys has been used to address the following research question: Does the 'You're Hired!' project lead to a change in student attitudes towards engineering? The other key metrics for project effectiveness, increased engineering design skills and enhanced $21^{\text {st }}$ Century skills, are not directly assessed in the student surveys. Separate assessment rubrics for measuring student growth in these areas are under development for use in the next school year. Evaluation of the pilot year in this paper, therefore, focuses on student attitudes toward and understanding of engineering careers.

\section{$\underline{\text { Sample Population }}$}

For this pilot year research project, the sample population consisted of three schools selected from the 15 total participating schools: School A, School B, and School C. The schools in the research cohort were chosen because they completed all of the following criteria: a letter of willingness to participate from one school administrator, an assent form from each participating student, pre-survey, three separate 'You're Hired!' activities, and a post-survey. If a student chose not to complete the assent form, their individual data is not included within data analysis as per Institutional Review Board (IRB) requirements. School A consisted of $837^{\text {th }}$ grade participants, School B had $2310^{\text {th }}$ grade participants, and School C had $1797^{\text {th }}$ and $8^{\text {th }}$ grade participants. Out of this research cohort group, 130 students were females and 155 were males.

\section{Data Collection}

Shortly after the start of the academic year, schools administered a letter of assent to each student to read and sign, along with an electronic pre-survey adapted from the Assessing Women and Men in Engineering (AWE) Core Middle School Immediate Pre-Participation Survey. ${ }^{[25]}$ This electronic survey establishes the baseline data of their initial exposure and knowledge about engineering and how this exposure and/or knowledge influences their decisions about future career paths and will provide a summative evaluation of Attitudes towards Engineering, SelfEfficacy, and Project Impact when compared to the end-of-the-year post-survey.

Both pre- and post-survey questions with the allowed categorical responses are listed in Table 1. Attitudes towards Engineering questions (\#1-7) relate to direct attitude and perception about the field of engineering and the interest in becoming an engineer. Self-Efficacy questions (\#8-9) were chosen to measure the student's attitude in regards to his/her understanding of the concept of the engineering design process and ability to successfully work with or lead a team to an effective solution. Project Impact questions (\#10-12) were used to gain insight into the students' perspective on the overall project.

Table 1: Electronic Pre- and Post-Survey Questions by Category

Category Questions with Categorical Answer Choices

Attitudes towards Engineering (pre- and post-surveys with agree, disagree, don't know)

1 Engineers mainly work on machines and computers.

2 Engineers mainly work with other people to solve problems.

3 Engineers work on things that help the world. 
4 Engineers can choose to do many different kinds of jobs.

5 Engineers mainly work on things that have nothing to do with me.

6 I don't know what engineers do.

7 Do you think you want to be an engineer? (yes, no, don't know)

Self-Efficacy (pre- and post-surveys with always, very often, sometimes, never)

8 In lab activities, I can use what I have learned to design a solution.

9 I can effectively lead a team to design and build a hands-on project.

Project Impact (post-surveys with a great deal, moderately, slightly, not at all)

10 Helped me understand problem solving better.

11 Increased my interest in studying engineering in college.

12 Increased my confidence in my ability to participate in engineering projects or activities.

After students took the electronic pre-survey, the school completed three separate 'You're Hired!' activities throughout the school year. Each activity provided students with a new challenge and a new engineering career to discover.

At the end of the academic year after the school had completed the third and final 'You're Hired!' activity, students completed the electronic post-survey. Each participating school received a year-end report anonymously summarizing their students' responses. This report also included a school by school comparison with all student and school names and identifiers removed.

\section{Data Analysis}

The data from the surveys was analyzed using the statistical software SAS and JMP 7. The data was analyzed to collect results from three groups of students; all students, females, and males. The researchers wanted to determine if the project had an impact on all students together, as well as determining impact on each gender. Descriptive statistics such as means and standard error were calculated as well as significance testing using chi-square and p-values.

To analyze the Attitude toward Engineering and Self-Efficacy questions, a chi-square analysis was performed to determine if there was a statistically significant difference in the shift in responses between the pre- and post-surveys. A chi-square analysis was chosen due to the categorical data represented from the survey questions.

To measure the impact of the project in regards to increasing students' interest and confidence in participating in engineering activities, the categorical data for the Project Impact questions was converted to a Likert scale. When converting the categorical responses to a Likert scale, the four responses for this question were: A great deal $=4$, Moderately $=3$, Slightly $=2$, and Not at All $=$ 1. Mean, standard error, and 95\% confidence intervals were calculated by gender for each question and male-female differences were analyzed using a one-way ANOVA.

\section{Results}

Table 2 shows the statistical comparison of pre- and post-survey results for all students for questions 1-9. The number of responses for the pre-survey was higher than for the post-survey. Pre-survey participation was over $95 \%$ of enrolled students and was due to repeated follow-up by 
teachers and the 'You're Hired!' research team. Post-survey participation was still over 80\%, but a similar level of follow up was not possible at the end of the school year when the surveys were administered. Questions with statistically significant differences are noted with an asterisk. When looking at responses for this data, the statistically significant changes occurred for: Question 1) 'Engineers mainly work on machines and computers', Question 2) 'Engineers mainly work with other people to solve problems', Question 4) 'Engineers can choose to do many different kinds of jobs', and lastly Question 5) 'Engineers mainly work on things that have nothing to do with me'. Descriptive statistics comparing pre- and post-survey results for all students can be found in Table 3. Discussion of the implications behind the results can be found in the discussion section of the paper.

Table 2: Statistical Analysis Comparing Pre-and Post-Survey Results for All Students

\begin{tabular}{|c|c|c|c|c|c|}
\hline \multirow[b]{2}{*}{ Question } & \multirow[b]{2}{*}{$\mathrm{X}^{2}$} & \multirow[b]{2}{*}{$\mathrm{df}$} & \multicolumn{2}{|c|}{$\mathrm{N}$} & \multirow[b]{2}{*}{ P-Value } \\
\hline & & & Pre & Post & \\
\hline $\begin{array}{l}1 \text { Engineers mainly work on machines and } \\
\text { computers. }\end{array}$ & 12.129 & 2 & 281 & 240 & $0.0023 *$ \\
\hline $\begin{array}{l}2 \text { Engineers mainly work with other people to } \\
\text { solve problems. }\end{array}$ & 36.359 & 2 & 278 & 239 & $<0.0001 *$ \\
\hline 3 Engineers work on things that help the world. & 1.906 & 2 & 278 & 240 & 0.3855 \\
\hline $\begin{array}{l}4 \text { Engineers can choose to do many different } \\
\text { kinds of jobs. }\end{array}$ & 22.243 & 2 & 278 & 238 & $<0.0001 *$ \\
\hline $\begin{array}{l}5 \text { Engineers mainly work on things that have } \\
\text { nothing to do with me. }\end{array}$ & 9.616 & 2 & 274 & 238 & $0.0082 *$ \\
\hline 6 I don't know what engineers do. & 4.002 & 2 & 265 & 237 & 0.1352 \\
\hline 7 Do you think you want to be an engineer? & 2.507 & 2 & 285 & 240 & 0.2855 \\
\hline $\begin{array}{l}8 \text { In lab activities, I can use what I have learned } \\
\text { to design a solution. }\end{array}$ & 6.115 & 3 & 280 & 239 & 0.1061 \\
\hline $\begin{array}{l}9 \text { I can effectively lead a team to design and build } \\
\text { a hands-on project. }\end{array}$ & 1.569 & 3 & 281 & 239 & 0.6664 \\
\hline
\end{tabular}

* significant at $\alpha=.05$ 
Table 3: Descriptive Statistics Comparing Pre-and Post-Survey Results for All Students

Don't

\section{Question}

1 Engineers mainly work on machines and computers.*

2 Engineers mainly work with other people to solve problems.*

3 Engineers work on things that help the world.

4 Engineers can choose to do many different kinds of jobs.*

5 Engineers mainly work on things that have nothing to do with me.*

6 I don't know what engineers do.

7 Do you think you want to be an engineer?

8 In lab activities, I can use what I have learned to design a solution.

9 I can effectively lead a team to design and build a hands-on project.

* $p<0.05$

\begin{tabular}{|c|c|c|c|c|c|}
\hline Survey & $\mathrm{N}$ & Agree & Disagree & Know & \\
\hline Pre & 281 & $62 \%$ & $26 \%$ & $13 \%$ & \\
\hline Post & 240 & $48 \%$ & $39 \%$ & $13 \%$ & \\
\hline Pre & 278 & $52 \%$ & $27 \%$ & $21 \%$ & \\
\hline Post & 239 & $77 \%$ & $15 \%$ & $8 \%$ & \\
\hline Pre & 278 & $79 \%$ & $9 \%$ & $13 \%$ & \\
\hline Post & 240 & $83 \%$ & $8 \%$ & $9 \%$ & \\
\hline Pre & 278 & $62 \%$ & $17 \%$ & $22 \%$ & \\
\hline Post & 238 & $80 \%$ & $10 \%$ & $10 \%$ & \\
\hline Pre & 274 & $15 \%$ & $62 \%$ & $23 \%$ & \\
\hline Post & 238 & $24 \%$ & $61 \%$ & $15 \%$ & \\
\hline Pre & 265 & $23 \%$ & $64 \%$ & $13 \%$ & \\
\hline Post & 237 & $17 \%$ & $72 \%$ & $11 \%$ & \\
\hline \multirow{5}{*}{$\begin{array}{l}\text { Pre } \\
\text { Post }\end{array}$} & & Yes & No & $\begin{array}{l}\text { Don't } \\
\text { Know } \\
\end{array}$ & \\
\hline & 285 & $23 \%$ & $45 \%$ & $32 \%$ & \\
\hline & 240 & $22 \%$ & $51 \%$ & $27 \%$ & \\
\hline & \multicolumn{5}{|c|}{ Very } \\
\hline & & Always & Often & Sometimes & Never \\
\hline Pre & 280 & $18 \%$ & $40 \%$ & $35 \%$ & $8 \%$ \\
\hline Post & 239 & $21 \%$ & $29 \%$ & $40 \%$ & $9 \%$ \\
\hline Pre & 281 & $19 \%$ & $30 \%$ & $39 \%$ & $13 \%$ \\
\hline Post & 239 & $16 \%$ & $27 \%$ & $43 \%$ & $14 \%$ \\
\hline
\end{tabular}

When analyzing the data based on gender, the results were different than for the population as a whole. Table 4 presents the statistical analysis to the responses for female and male students, while Table 5 summarizes the descriptive statistics. In the descriptive statistics table for females and males, the data within the table is displayed as (pre-survey response: post-survey response) with the statistically significant changes represented with an asterisk by the gender.

The results show there is a statistically significant difference between the pre- and post-survey responses for female students for Questions 1), 2), 3), 4), and 5). Responses for male students found Questions 2), 4), and 8) as being statistically significant between pre- and post-surveys. 
Table 4: Statistical Analysis Comparing Pre-and Post-Survey Results for Female and Male Students

\begin{tabular}{|c|c|c|c|c|c|c|}
\hline \multirow[b]{2}{*}{ Question } & \multirow[b]{2}{*}{ Gender } & \multirow[b]{2}{*}{$\mathrm{x}^{2}$} & \multirow[b]{2}{*}{ df } & \multicolumn{2}{|c|}{$\mathrm{N}$} & \multirow[b]{2}{*}{ P-Value } \\
\hline & & & & Pre & Post & \\
\hline 1 Engineers mainly work on machines & Female & 14.539 & 2 & 127 & 113 & $0.0007 *$ \\
\hline and computers. & Male & 4.909 & 2 & 154 & 127 & 0.0859 \\
\hline 2 Engineers mainly work with other & Female & 19.640 & 2 & 127 & 113 & $<0.0001^{*}$ \\
\hline people to solve problems. & Male & 19.635 & 2 & 151 & 126 & $<0.0001 *$ \\
\hline 3 Engineers work on things that help & Female & 8.501 & 2 & 126 & 113 & $0.0143 *$ \\
\hline the world. & Male & 0.556 & 2 & 152 & 127 & 0.7573 \\
\hline 4 Engineers can choose to do many & Female & 17.127 & 2 & 127 & 113 & $0.0002 *$ \\
\hline different kinds of jobs. & Male & 7.351 & 2 & 151 & 125 & $0.0253 *$ \\
\hline 5 Engineers mainly work on things & Female & 8.437 & 2 & 127 & 112 & $0.0147 *$ \\
\hline that have nothing to do with me. & Male & 3.500 & 2 & 147 & 126 & 0.1737 \\
\hline \multirow[t]{2}{*}{6 I don't know what engineers do. } & Female & 2.675 & 2 & 122 & 111 & 0.2625 \\
\hline & Male & 1.578 & 2 & 143 & 126 & 0.4544 \\
\hline \multirow{2}{*}{$\begin{array}{l}7 \text { Do you think you want to be an } \\
\text { engineer? }\end{array}$} & Female & 0.412 & 2 & 130 & 113 & 0.8138 \\
\hline & Male & 2.399 & 2 & 155 & 127 & 0.3013 \\
\hline \multirow{2}{*}{$\begin{array}{l}8 \text { In lab activities, I can use what I } \\
\text { have learned to design a solution. }\end{array}$} & Female & 2.904 & 3 & 129 & 113 & 0.4067 \\
\hline & Male & 8.889 & 3 & 151 & 126 & $0.0308^{*}$ \\
\hline \multirow{2}{*}{$\begin{array}{l}9 \text { I can effectively lead a team to } \\
\text { design and build a hands-on project. }\end{array}$} & Female & 0.867 & 3 & 129 & 113 & 0.8334 \\
\hline & Male & 3.327 & 3 & 152 & 126 & 0.3438 \\
\hline
\end{tabular}

* significant at $\alpha=.05$ 
Table 5: Descriptive Statistics Comparing Pre-and Post-Survey Results for Female and Male Students

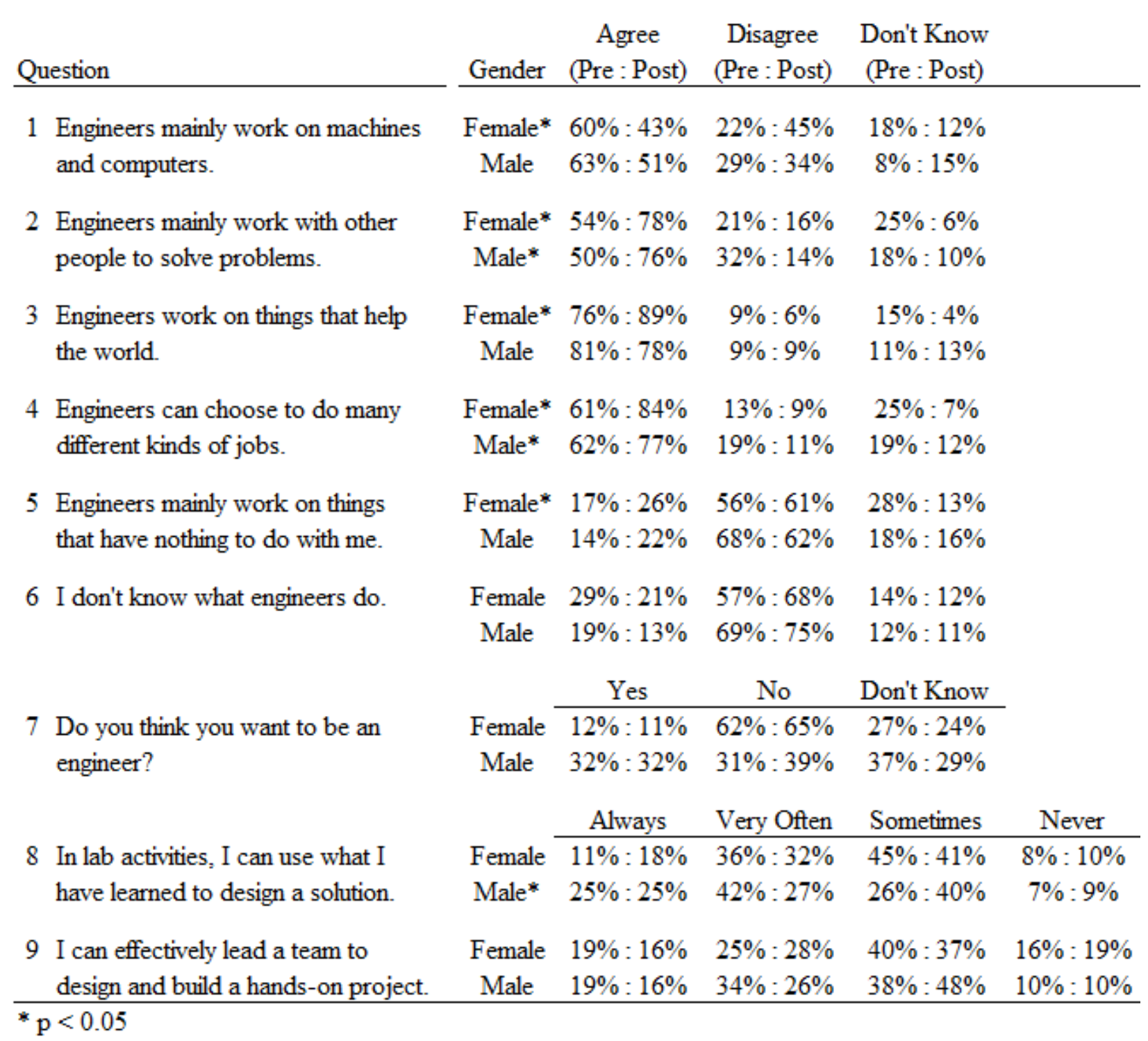

The post-survey also contained questions regarding the impact the 'You're Hired!' project had on students, with descriptive results listed in Table 6 and one-way ANOVA analysis in Table 7, Table 8, and Table 9. Due to the fact that these questions were only asked during the post-survey, the data could not be used to determine statistically significant changes between pre- and postsurvey responses. Responses were converted to a Likert Scale in order to statistically compare the responses between genders, with 'A Great Deal' = 4, 'Moderately' = 3, 'Slightly' = 2, and 'Not At All' = 1 . 
Table 6: Descriptive Statistics for Program Impact for Each Gender

$95 \%$ C.I.

Question Gender N Mean Std Error* Lower Upper

10 Helped me understand problem

$\begin{array}{cccccc}\text { Female } & 113 & 2.593 & 0.0870 & 2.422 & 2.764 \\ \text { Male } & 127 & 2.339 & 0.0821 & 2.177 & 2.500\end{array}$

11 Increased my interest in studying

Female $\quad \begin{array}{lllll}110 & 2.009 & 0.0991 & 1.814 & 2.204\end{array}$ engineering in college **

Male $\quad \begin{array}{lllll}127 & 2.354 & 0.0923 & 2.173 & 2.536\end{array}$

12 Increased my confidence in my $\quad \begin{array}{lllll}112 & 2.214 & 0.0971 & 2.023 & 2.406\end{array}$

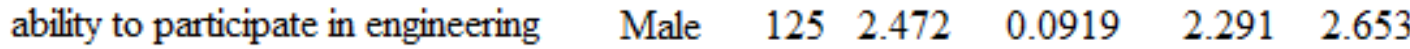
projects or activities

* Std Error uses a pooled estimate of error variance, ** $p<0.05$

Table 7: One-Way ANOVA for Project Impact Question 10 When Comparing Gender

\begin{tabular}{|c|c|c|c|c|c|}
\hline Source & DF & Sum of Squares & Mean Square & $\mathrm{F}$ & P-Value \\
\hline Gender & 1 & 3.868 & 3.868 & 4.519 & $0.0345 *$ \\
\hline Error & 238 & 203.715 & 0.856 & & \\
\hline Total & 239 & 207.583 & & & \\
\hline
\end{tabular}

* significant at $\alpha=.05$

Table 8: One-Way ANOVA for Project Impact Question 11 When Comparing Gender

\begin{tabular}{|c|c|c|c|c|c|}
\hline Source & $\mathrm{DF}$ & Sum of Squares & Mean Square & $\mathrm{F}$ & P-Value \\
\hline Gender & 1 & 7.026 & 7.026 & 6.499 & $0.0114 *$ \\
\hline Error & 235 & 254.046 & 1.081 & & \\
\hline Total & 236 & 261.072 & & & \\
\hline
\end{tabular}

* significant at $\alpha=.05$ 
Table 9: One-Way ANOVA for Project Impact Question 12 When Comparing Gender

\begin{tabular}{|c|c|c|c|c|c|}
\hline Source & DF & Sum of Squares & Mean Square & $\mathrm{F}$ & P-Value \\
\hline Gender & 1 & 3.923 & 3.923 & 3.718 & 0.0550 \\
\hline Error & 235 & 248.009 & 1.055 & & \\
\hline Total & 236 & 251.932 & & & \\
\hline
\end{tabular}

\section{Discussion}

A student's image of what engineering is and what engineers look like can stem from multiple sources. Whether those sources of information are accurate or not may leave students with a misinformed idea about what engineering is. When looking at pre-survey responses, before the first 'You're Hired!' project took place in a school, a large majority of students already had ideas of what engineering is and the type of work engineers do.

Pre-survey results showed that some of the ideas students had about engineering were correct, such as $79 \%$ of students stating that engineers work on things that help the world and $62 \%$ agreeing that engineers can choose many different kinds of jobs. However other ideas were not as accurate. For example, 62\% thought that engineers mainly work on machines and computers and only $52 \%$ agreed that engineers work with other people to solve problems. The percent of students that think they want to be an engineer was $12 \%$ for females and $32 \%$.

\section{Quantitative Analysis of All Student Responses}

The quantitative analysis of responses from all students indicated that Questions 1), 2), 4), and 5) show statistically significant pre/post changes. Responses to Questions 1), 2), and 4) suggest that students had a more accurate understanding of engineering when they took the post-survey versus the pre-survey. Question 1) which stated, 'Engineers mainly work on machines and computers' had a post-survey level of agreement of $48 \%$ which was a decrease of $14 \%$ from the pre-survey response. Question 2) 'Engineers mainly work with other people to solve problems' had a post-survey response of $77 \%$ that agreed which was an increase of $25 \%$ from the presurvey. For Question 2) not only did the number of students that disagreed with the statement decrease by $12 \%$, but the number of students that didn't know dropped $13 \%$ from the pre-survey response. When looking at Question 4), 'Engineers can choose to do many different kinds of jobs' the post-survey level of agreement was $80 \%$ which was an increase of $18 \%$ from the presurvey responses. For this question the number of students that disagreed dropped by $7 \%$ and the number of students that were unsure and chose 'don't know' decreased by over half.

Question 5) which stated, 'Engineers mainly work on things that have nothing to do with me' showed a statistically significant change in what we consider a negative direction with a $9 \%$ increase resulting in $24 \%$ of students indicating that engineers work on things that do not relate to them. When looking at shifts in the other responses, the percent of students that disagreed with the statement stayed basically constant with a change of only $1 \%$. The majority of the increase came from the number of students that chose 'don't know' which decreased by $8 \%$ from pre- to post-survey data. Taking together the pre- and post-survey data comparison for questions 1-6, it 
appears that by the end of the project more students had a better, more accurate understanding of engineering and less students claimed to be unsure.

It is possible that some students may not have interpreted every survey question in the same way that researchers intended. An example of this is seen in what appear to be contradictory changes in the responses to Questions 3) and 5). Responses to Question 3) did not change significantly from pre- to post-survey, and showed an exceptionally high percentage of students (83\% for post-survey) that agreed 'Engineers work on things that help the world.' In contrast, the percentage of students agreeing with the statement in Question 5) 'Engineers work on things that have nothing to do with me.' increased significantly from $15 \%$ to $24 \%$. It is possible that due to the negative way in which the question was stated, students could have misinterpreted it resulting in a significant change in the unfavorable direction. In the future, the 'You're Hired!' research team will work with a cohort group of students to ask about their thoughts of questions that are presented. This will provide a better understanding of how this particular group of students interprets the questions that are being asked in the surveys.

Despite the generally positive changes in student understanding of engineering, there was no statistically significant change in the percentage of students that think they want to be an engineer, as shown by responses to Question 7). It is important to note that the focus of this initial analysis of the 'You're Hired!' project is on changes in student understanding and attitudes towards engineering. These changes are seen as a first step in encouraging more students to pursue engineering careers. Ongoing research will look at the influence of continued participation in the 'You're Hired!' project over multiple school years to determine if attitude changes eventually lead to changes in student career plans.

When looking at responses to the Self-Efficacy questions, neither Question 8) nor Question 9) was statistically significant when comparing pre- to post-survey data. As shown in Table 3, for both questions there was a range of responses, but with most students stating that 'Sometimes' or 'Very Often' they could design a solution or lead a team. The amount of students that chose 'Always' and 'Never' stayed relatively constant, at most shifting by 3\%. For Question 8), 'In lab activities, I can use what I have learned to design a solution,' the shift in the largest response category went from 'Very Often' to 'Sometimes'. For Question 9) which stated, 'I can effectively lead a team to design and build a hands-on project,' the student responses stayed relatively constant across all categories.

\section{Quantitative Analysis by Gender}

As seen in Table 4, for females only, Questions 1), 2), 3), 4), and 5) showed significant pre/post changes. Data from male students showed different significant changes. For male only responses, Questions 2), 4), and 8) showed significant changes from pre- to post-survey responses.

For female students only, Question 1) responses show the percentage of students who disagreed that engineers mainly work on machines and computers was twice as high in the post-survey as in the pre-survey. Question 2) had a post-survey level of agreement that increased to $78 \%$ from $54 \%$ for female students stating they agree that engineers work with others to solve problems. The percentage of students that disagreed with the statement dropped by $5 \%$ and the percent that 
didn't know dropped by $19 \%$ as shown in Table 5. Post-survey responses for Question 3) indicate that $89 \%$ of female students thought that engineers work on things that help the world.

This is an increase from pre-survey response levels of $76 \%$ and is due primarily to a decrease in the fraction of students stating they don't know. Female student data for Question 4) showed similar trends. In the post-survey $84 \%$ of female students thought that engineers can choose to do many different kinds of jobs, compared to $61 \%$ in the pre-survey. When looking at the other response categories for this question, the percentage of students that disagreed with this statement dropped by only $4 \%$ and the number of students that didn't know dropped $18 \%$ which indicates that the students that didn't know before the 'You're Hired!' project now have a better idea of the variety of careers engineers can have. Question 5) for females resulted in the same type of responses as is seen for all students. Overall, females appear to positively change their understanding of the engineering field, with higher percentages and similar or higher changes than observed for males on Questions 1)-4).

Data from male students showed that responses to Question 2) shifted in such a way that in the post-survey data $76 \%$ of male students think that engineers mainly work with other people to solve problems, up from only $50 \%$ in the pre-survey. As with the female students this occurred due to decreases in both the disagree and don't know response categories. However for male students the largest decrease was in students that disagreed, where the percentage was reduced by more than half from $32 \%$ to $14 \%$ in pre-to post-survey data. Question 4) results for male students were also similar to the female student results and showed a significant shift in the percentage who agreed that 'Engineers can do many different kinds of jobs.' And unlike female students, male students had a significant change in responses to Question 7), 'In lab activities, I can use what I have learned to design a solution.' The percentage of students that chose 'Always' and 'Never' stayed almost exactly the same. The significant difference was a result a shift in student responses from 'Very Often' during the pre-survey to 'Sometimes' for the post-survey.

In regards to the results shown in the statistical and descriptive statistics tables it should be noted that the changes in student perceptions of engineering cannot be linked directly to the 'You're Hired!' project. Because the 'You're Hired!' project is a set of 3 separate activities that are spread out over the course of an entire school year, other events that have taken place in, or out of, the classroom may have also affected the post-survey responses. For example, the transition from one grade to the next may have brought more difficult lab experiences for the same set of students. At the end of the year, those students may be less confident in their ability to conduct a lab experiment based on their experiences with more challenging experiments in which they could not come up with a solution as often. Other possible influences outside of the 'You're Hired!' project in a school could be: classroom instruction, teacher attitudes towards STEM, guest speakers, parents talking with students after hearing about their experiences with the 'You're Hired!' activities, or teachers taking pieces of the 'You're Hired!' approach and incorporating it into their everyday class. While such outside influences may have had an effect on the results from the post-survey, the 'You're Hired!' project is thought to have influenced the shift in responses.

To determine if this shift can be more clearly linked to the 'You're Hired!' project, a controlled study is being conducted in one middle school during the current 2013-2014 school year. The 
school system is large enough to have multiple pods of students per grade. Students within a pod stay together throughout the day and each pod has its own set of teachers. Because these pods are segregated and student placement within the pods is completely random, this system creates an ideal situation for a 'You're Hired!' control group. A total of four pods, two pods from two separate grades, are participating in the study. In each grade, both pods complete the pre- and post-surveys, but only one pod completes the three 'You're Hired!' activities. Results from this research will be presented in a future paper.

Project Impact Analysis

Questions 10), 11), and 12) relate to student perceptions of project impact. The descriptive statistics for project impact for each gender can be found in Table 6. In general, the 'You're Hired!' project appears to have an impact with all mean values at a value of 2 ('Slightly') or higher. Because these questions were only asked during the post-survey, the data could not be used to determine statistically significant changes between pre- and post-survey responses. The responses were converted to a Likert Scale so that significance could be determined between genders. Question10) and Question 11) had a statistically significant difference between female and male results.

Question 10) responses indicated that on average female students thought the project 'helped me understand problem solving better' more than did male students. Conversely, Question 11) showed significantly more male students than female students indicating that the project increased their interest in studying engineering in college. These differing male and female responses to whether or not students were impacted to study engineering in college tie in with responses to Question 7), 'do you think you want to be an engineer?' where a higher percentage of male students claimed to want to be an engineer than female students.

While the project appears to have at least slightly impacted the participating students, there was not a measurable change in the percentage of students that think they might want to become engineers. Engineering is Elementary (EiE), a program that works with grades 3-5, resulted in an increase (from a mean of 1.42 to 1.69 on a 0-4 Likert scale) in students that stated, "I would enjoy being an engineer when I grow up." [17] The research team is learning and comparing against existing programs, such as EiE, in an effort to not only see changes in attitude that were observed after a single year of participation in 'You're Hired!', but also see changes to student career plans as well. It should also be recognized that the responses to the Project Impact questions were based on each student's perspective of themselves and the project and may not reflect actual changes in understanding, interest, or confidence. In future research, there will be additional questions on both the pre-and post-surveys so that project impact can be measured more effectively.

The 'You're Hired!' project is still relatively new and under development. The results presented in this paper on student attitudes and understanding during the 2012-2013 pilot year are only the first set of collected assessment data. Together with planned assessment of students' engineering design and $21^{\text {st }}$ Century skills, they will guide future revisions to YH. Features from other successful K12 engineering programs will also continue to be incorporated. The ultimate goal is to develop an effective engineering education project that can then be scaled and sustained across a broader region. With that goal in mind, one very promising aspect of $\mathrm{YH}$ is that students, 
teachers, administrators, and community members who see the project in action are very enthusiastic about participating. As the project continues to be developed and effectiveness can be demonstrated, there is good potential for wide adoption.

\section{Conclusion}

The 'You're Hired!' project looks promising based on data collected from the pilot year's preand post-surveys. Overall student responses showed a significant, but small, positive change in their understanding and attitudes towards engineering. The pilot year data does not indicate if the changes in attitudes towards engineering are in response to the 'You're Hired!' project specifically or a combination of various student experiences throughout the course of the school year. A controlled experimental study is currently being conducted to determine whether the observed changes in attitude can be attributed to the project. This ongoing research will also assist in understanding what changes can be made to make the project more effective. Future plans for the project include professional development for teachers to extend engineering design principles from 'You're Hired!' into the daily classroom, research to identify program elements that contribute to positive student changes, expansion of its implementation across a tri-state region, and development of a model for sustainability and expansion to other regions.

\section{References}

1. J. Kimrey, "Engineering futures are always bright," Chron, 26 July 2013 . [Online]. Available: http://www.chron.com/jobs/article/Engineering-futures-are-always-bright-4688904.php. [Accessed 03 January 2014].

2. Committee on Public Understanding of Engineering Messages and National Academy of Engineering, "Changing the Conversation: Messages for Improving Public Understanding of Engineering," National Academies Press, 2008.

3. C. Hill, C. Corbett and A. St. Rose, "Why So Few? Women in Science, Technology, Engineering, and Mathematics," American Association of University Women, Washington, DC, 2010.

4. M. Knight and C. Cunningham, "Draw an Engineer Test (DAET): Development of a Tool to Investigate Students Ideas about Engineers and Engineering," ASEE Annual Conference and Exposition, 2004.

5. H. Marshall, M. Lynne and L. Joyce, "Public Attitudes to and Perceptions," British Market Research Bureau, 2007.

6. E. Fussell Policastro, "Engineers can change the world," InTech, April 2009. [Online]. Available: http://www.isa.org/InTechTemplate.cfm?template=/ContentManagement/ContentDisplay.cfm\&ContentID=753 81. [Accessed 03 January 2014].

7. H. O. Yurtseven, "How Does the Image of Engineering Affect Student Recruitment and Retention? A Perspective from the USA*," Global Journal of Engineering Education, vol. 6, pp. 17-23, 2002.

8. K. Young, "Recruiting Future Engineers through Effective Guest Speaking in Elementary School Classrooms," in Meeting the Growing Demand for Engineers and Their Educators 2010-2020 International Summit, Munich, 2007.

9. "Science and Engineering Degrees: 1966-2010," National Science Foundation, June 2013. [Online]. Available: http://www.nsf.gov/statistics/nsf13327/content.cfm?pub_id=4266\&id=2. [Accessed 03 January 2014].

10. O. Eniola-Adefeso, "Engaging K-12 Students in the Engineering Classroom: A Creative Use of Undergraduate Self-Directed Projects," Chemical Engineering Education, vol. 44, pp. 280-286, Fall 2010.

11. K. Patterson, J. Grenny, D. Maxfield, R. McMillan and A. Switzler, Influencer - The Power to Change Anything, New York, NY: McGraw-Hill Professional Publishing, 2007. 
12. A. Bandura, "Self-Efficacy: Toward a unifying theory of behavioral change," Phycological Review, vol. 84, pp. 191-215, 1977.

13. T. D. Fantz, T. J. Siller and M. A. DeMiranda, "Pre-Collegiate Factors Influencing the Self-Efficacy of Engineering Students," Journal of Engineering Education, vol. 100, pp. 604-623, 2011.

14. L. Dawes and G. Rasmussen, "Activity and engagement - Keys in connecting engineering with secondary school students," 2006.

15. A. Jeffers, A. Safferman and S. Safferman, "Understanding K-12 Engineering Outreach Programs," Journal of Professional Issues In Engineering Education And Practice, vol. 130, pp. 95-108, 2004.

16. C. Cunningham and C. Lachapelle, "Engaging ALL Students in Engineering," American Society for Engineering Education, 2012.

17. C. Cunningham and C. Lachapelle, "The Impact of Engineering is Elementary (EiE) on Students' Attitudes Towards Engineering and Science," American Society for Engineering Education, 2010.

18. C. Lachapelle, P. Phadnis, J. Hertel and C. Cunningham, "What is Engineering? A Survey of Elementary Students," 2012.

19. M. Mooney and T. Laubach, "Adventure Engineering: A Design Centered, Inquiry Based Approach to Middle Grade Science and Mathematics Education," Journal of Engineering Education, vol. 91, no. 3, pp. 309-318, 2002.

20. R. W. Habash and C. Suurtamm, "Engaging High School and Engineering Students: A Multifaceted Outreach Program Based on a Mechatronics Platform," IEEE, vol. 53, no. 1, pp. 136-143, 2010.

21. C. Davis, M. Yeary and J. Sluss, "Reversing the Trend of Engineering Enrollment Declines With Innovative Outreach, Recruiting, and Retention Programs," IEEE, vol. 55, no. 2, pp. 157-163, 2012.

22. C. Hmelo-Silver, R. Golan Duncan and C. Chinn, "Scaffolding and Achievement in Problem-Based and Inquiry Learning: A Response to Kirschner, Sweller, adn Clark (2006)," Educational Psychologist, vol. 42, no. 2, pp. 99-107, 2007.

23. D. Edelson, "Learning-for-use: A framework for the design of technology-supported inquiry activities," Journal of Research in Science Teaching, vol. 38, no. 3, pp. 355-385, 2001.

24. "Grade 5 Measurement \& Data," Common Core State Standards Initiative - Preparing America's Students for College \& Career, 2014. [Online]. Available: http://www.corestandards.org/Math/Content/5/MD/. [Accessed 22 March 2014].

25. "AWE instrument user guide - pre-college surveys," Assessing Women and Men in Engineering (AWE), [Online]. Available: https://www.engr.psu.edu/awe/secured/director/AWEhome.aspx. [Accessed 2011]. 